meeting was sponsored by the College and the Association of Anaesthetists and was attended by representatives of all Colleges and Faculties, the General Medical Council, the DHSS, the Medical Defence Unions and other interested parties. A report of this meeting will appear in due course. Meanwhile, the College will continue to have discussions with certain Colleges and other bodies in an effort to provide a speedy and confidential service to help doctors who are in difficulties because of psychiatric illness.

'At the meeting of the Regional Advisers on 22 March there was further discussion about the involvement of Regional Advisers in the work of the College Divisions and it was agreed that the role of Regional Advisers should be extended so as to involve them in the development of rotational training programmes in Regions, and where practicable, in co-ordinating the activities of psychiatric tutors in the Regions. It was also agreed that Regional Advisers would, wherever possible, represent the College on Appointment Committees for Senior Registrars [Bulletin, August $1982,6,145-46]$.

'A Special Committee has been set up to consider the College's response to the Short Report and the Government's reaction to that report. The Special Committee is collecting information about the manpower and training implications for psychiatry of the proposal to increase the number of consultants and reduce the number of junior doctors. The Special Committee's comments will be reported in due course.

'The Special Committee which is considering the College's response to the Research Report on the use of ECT met on 22 February. Among other matters discussed, it was agreed to encourage Divisions of the College to consider holding meetings of consultants who would take a particular interest in the administration of ECT in their hospitals and units, and it was made known that Dr John Pippard, who conducted the Research Project, would be willing to visit the Divisions in order to discuss the appropriate methods of administering ECT and ways in which improvements could be achieved. A poster entitled "How to Give ECT" has been prepared and is being distributed.

'The House Committee continues to arrange for the refurbishment of 17 Belgrave Square and work is now in progress to redecorate and improve the Members' room on the ground floor and to provide an additional Lecture Room.

'In conjunction with the Association of University Teachers of Psychiatry and the Association of Psychiatrists in Training, the College participated in a successful weekend conference in Cambridge from 26 to 28 March on training and recruitment in psychiatry. A report of this conference will be published in due course [Bulletin, June 1982, 6, 105; 107].

'The Finance Committee has approved the grant of a sum of $£ 2,500$ to the Research Committee in order to carry out a prospective study of the careers of women psychiatrists. This study will be undertaken by Dr Audrey Ward of the Medical Care Research Unit at the University of Sheffield.

'Finally, may I thank Dr David Enoch, Professor Copeland, Dr Cookson and Dr Ansari and all of our colleagues and friends in Liverpool for the arrangements which they have made for this very successful Quarterly Meeting.'

\title{
A need for a Research Register?
}

The College ECT survey questionnaire in March 1980 asked 'Are you doing research on any aspect of the use of ECT?' From the 61 who replied 'yes', it appears that there were 49 separate individuals or groups involved. By April 1982 I knew that 12 of these had published, or had had accepted, at least some of their work. A short questionnaire was sent to the other 37 to find out how their work was going on and to canvass opinion on the possible usefulness of the College setting up a Register of Research.

Of the 37 questioned, one had died and nine did not reply. Of the 27 (73 per cent) who replied, seven had completed and published their work and six others had published some of their work. Eight were continuing research on ECT but had not yet reported. Six had discontinued without publishing, usually because they could not find enough time or money or enlist the support and help of colleagues or assistants.

Only three would not have found a Register useful, two were doubtful and 20 thought it would have been helpful. All the 25 who answered the question were agreeable to the inclusion in a Register of their names, addresses and details of projects.

Research projects in ECT which were started after 1980 have not been considered. The amount of work in this one small area of enquiry is surprisingly large. Half of the 49 individuals or groups are known to have reported their work and others will be doing so.

These findings may encourage the Research Committee of the College to undertake the considerable task of setting up and maintaining an up-to-date Register of all psychiatric research.

John Pippard 